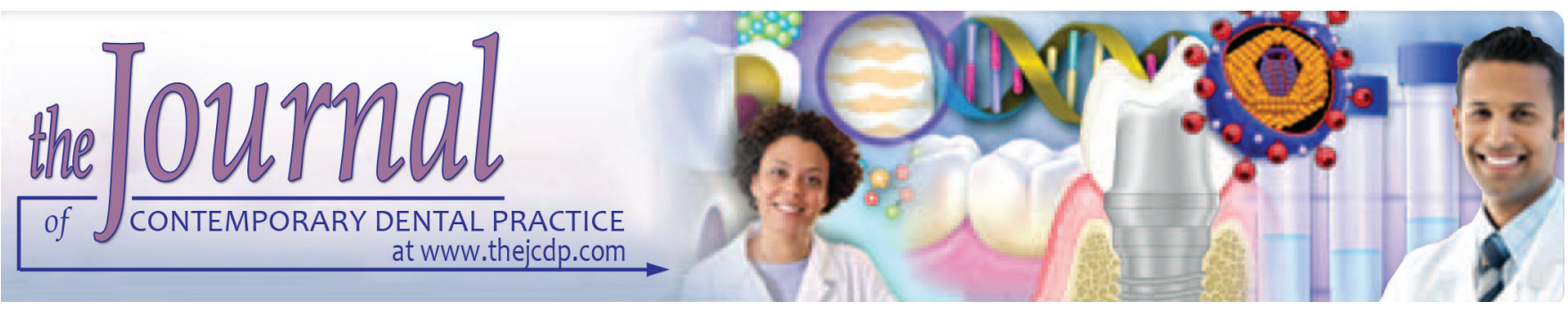

\title{
Comparative Evaluation of Stress developed on Rotary Retreatment Instruments during Retrieval of Gutta-percha
}

\author{
${ }^{1}$ Dhanasekaran Sihivahanan, ${ }^{2} \mathrm{~T}$ Vinay Kumar Reddy, ${ }^{3}$ Anchu Rachel Thomas, ${ }^{4}$ Natarajan Senthilnathan \\ ${ }^{5}$ Murali Sivakumar, ${ }^{6}$ Sushmita Shivanna
}

\begin{abstract}
Aim: The aim of the study is to compare the maximum stress distribution on the rotary retreatment instruments within the root canal at cervical, middle, and the apical one-third during retreatment of gutta-percha.
\end{abstract}

Materials and methods: A human mandibular premolar was scanned, and three-dimensional geometry of the root was reconstructed using finite element analysis (FEA) software package (ANSYS). The basic model was kept unchanged; tooth models were created using the same dimensions and divided into two groups as follows: Group I: ProTaper Universal retreatment system and group II: Mtwo rotary retreatment system. The stress distribution on the surface and within the retreatment files was analyzed numerically in the FEA package (ANSYS).

Results: The FEA analysis revealed that the retreatment instruments received the greatest stress in the cervical third, followed by the apical third and the middle third. The stress generated on the ProTaper Universal retreatment system was less when compared with the Mtwo retreatment files.

Conclusion: The study concludes that the retreatment instruments undergo higher stress in the cervical third region, and further in vivo and in vitro studies are necessary to evaluate the relationship between instrument designs, stress distribution, residual stresses after use, and the torsional fracture of the retreatment instrument.

Clinical significance: The stress developed on the rotary retreatment instruments during retrieval of gutta-percha makes the instrument to get separated. There is no instrument system, i.e., suitable for all clinical situations and it is important to

1-5 Department of Conservative Dentistry and Endodontics, SRM Kattankulathur Dental College and Hospital, Kancheepuram Tamil Nadu, India

${ }^{6}$ Department of Conservative Dentistry and Endodontics Sathyabama Dental College and Hospital, Chennai, Tamil Nadu India

Corresponding Author: Dhanasekaran Sihivahanan, 92, S1 Rajendran Street, Thiru Nagar, Valasaravakkam, Chennai Tamil Nadu, India, Phone: +919940316750, e-mail: endosihi@ gmail.com understand how the structural characteristics could influence the magnitude of stresses on the instrument to prevent its fracture in use.

Keywords: Finite element analysis, Mtwo retreatment files, ProTaper retreatment files, Retreatment, Stress distribution.

How to cite this article: Sihivahanan D, Reddy TVK, Thomas AR, Senthilnathan N, Sivakumar M, Shivanna S. Comparative Evaluation of Stress developed on Rotary Retreatment Instruments during Retrieval of Gutta-percha. J Contemp Dent Pract 2017;18(6):484-489.

Source of support: Nil

Conflict of interest: None

\section{INTRODUCTION}

The success of an endodontic therapy revolves around the quality of instrumentation, disinfection, threedimensional (3D) obturation of the root canal, and, most importantly, preventing reinfection. ${ }^{1}$

Endodontic intervention, despite having a high success rate, may not attain the desired response and failures may occur. ${ }^{2}$ Endodontic failures can be attributed to inadequacies in instrumentation, obturation, iatrogenic events, or reinfection of the root canal system. ${ }^{3}$

To reduce the risk of endodontic failures during retreatment procedures, it is mandatory to remove as much sealer and gutta-percha as possible to uncover remnants of necrotic tissues or bacteria. ${ }^{4}$ However, very often the gutta-percha is well compacted and offers resistance to instruments, leading to the incomplete removal mostly in the apical third region, further impairing root canal disinfection and reshaping. ${ }^{5}$

Techniques described for gutta-percha removal include the use of endodontic hand files and solvents, heat carrying instruments, ultrasonic tips and files, and rotary instruments. In many clinical situations, combining different techniques may be the most efficient method. ${ }^{6}$ 
Although many techniques have been proposed for removing root filling materials, rotary nickel titanium (NiTi) instruments have proved to be effective and faster in removing filling materials. ${ }^{7}$

The ProTaper Universal retreatment files are designed to facilitate the removal of root canal filling materials and comprise three retreatment instruments (D1, D2, and D3). They have various tapers and diameters at the tip, which are size 30, 0.09 taper, size 25, 0.08 taper, and size 20, 0.07 taper and are available in full length, D1 $=16 \mathrm{~mm}$, $\mathrm{D} 2=18 \mathrm{~mm}$, and D3 = $22 \mathrm{~mm}$. D1, D2, and D3 are recommended to remove filling materials from the coronal, middle, and apical portions of canals respectively. ${ }^{6}$

Another rotary NiTi retreatment system is the Mtwo retreatment system; the files are available in sizes of $15 / 0.05$ and $25 / 0.05$. A speed of $280 \mathrm{rpm}$ is recommended by the manufacturer for efficient removal of gutta-percha. ${ }^{8}$

It has been observed clinically that even the use of new NiTi instruments poses a potential risk for fracture during instrumentation. The NiTi instruments can undergo fracture within their elastic limit without any visible sign of previous permanent deformation. ${ }^{7}$ Measuring the stress generated on the instrument during actual clinical use would be impossible, hence, a mathematical stimulation was designed to estimate the stress generated on the instrument. ${ }^{9}$

Finite element analysis (FEA) comprises computer models of material design. These models are stressed and analysis for specific results is undertaken. When a structure is subjected to force, FEA can be used to determine the distribution of stress and strain based on the properties of the material. ${ }^{10}$

\section{AIM}

The aim of the study is to compare the maximum stress distribution on the rotary retreatment instruments within the root canal at cervical, middle, and the apical one-third during retreatment of gutta-percha.

\section{MATERIALS AND METHODS}

The standard body for which the stress analysis was performed was a human mandibular premolar extracted for routine clinical reasons.

\section{Sample Preparation}

Gross debris and stains were removed from the teeth with ultrasonic scaler (Acteon PVT, Pitampura, New Delhi, India). The tooth was examined under a stereomicroscope ( $\times 40$ magnification) (Olympus SZX16) to ensure that it was free of cracks, defects, and caries and then stored in physiological saline solution (Nirma Ltd, Ahmedabad, Gujarat, India) until use. For easy reference of working length, the tooth was decoronated at the level of cementoenamel junction. The canal patency was checked with \#15-K file (Mani, Utsunomiya Tochigi, Japan). The working length was determined by placing \#15-K file until it was just visible at the apical foramen and $1 \mathrm{~mm}$ was subtracted to attain the working length. Cleaning and shaping were done using ProTaper Universal rotary NiTi (Dentsply Maillefer, Ballaigues, Switzerland) system up to F3, using intermittent rinsing of $1 \mathrm{~mL}$ of $5.25 \%$ sodium hypochlorite (Neelkanth Chemicals, Vadodara, Gujarat, India) followed by a final rinse with $5 \mathrm{~mL}$ of normal saline (Nirma Ltd, Ahmedabad, Gujarat, India).

\section{Development of the FEA Model}

The tooth was scanned using a spiral computed tomography (Siemens Health care, Henkestr., Erlangen, Germany) using settings of $220 \mathrm{kV}, 100 \mu \mathrm{A}$, a focus of $5 \mu \mathrm{m}$, and a slice sickness of $100 \mu \mathrm{m}$. The data were saved in a computer, a 3D geometry of the root canal was reconstructed, and FEMs were developed using a commercial FEA software package (ANSYS). Modeling was done using software called Pro/Engineer. Using the software, surfaces of the models were created and controlled to get exact shapes at microscopic levels. The modeling of tooth and the guttapercha was done according to previous studies (Table 1). ${ }^{11}$

The periodontal ligament, cancellous bone, and cortical bone were constructed based on dimensions obtained from the literature. ${ }^{11}$ The periodontal ligament was simulated around the root surface at a thickness of $200 \mu \mathrm{m}$. Cementum and sealer were not modeled separately and were considered to be incorporated in the root dentin and gutta-percha respectively.

The tooth model has 3,680 nodes and 2,514 elements. To avoid the influence of complex anatomic features, the roots were modeled with an oval external cross section in which the buccolingual depth was twice the mesiodistal width. Dentin thickness was uniform through root length $(2 \mathrm{~mm})$.

The basic model was kept unchanged; two tooth models were created using the same dimensions and divided into two groups:

- Group I: ProTaper Universal retreatment system

- Group II: Mtwo rotary retreatment system.

From the literature, the cross-sectional design, diameter, and taper of the retreatment files were drawn using

Table 1: Properties of the tooth model and gutta-percha

\begin{tabular}{lll}
\hline & $\begin{array}{l}\text { Modulus of } \\
\text { elasticity }\left(\mathrm{N} / \mathrm{mm}^{2}\right)\end{array}$ & $\begin{array}{l}\text { Poisson's } \\
\text { ratio }\end{array}$ \\
\hline Enamel & $8.41 \times 104$ & 0.300 \\
Dentin & $2.00 \times 104$ & 0.310 \\
Periodontal ligament & $5.00 \times 101$ & 0.490 \\
Alveolar bone & $1.40 \times 104$ & 0.150 \\
Gutta-percha & $3.00 \times 102$ & 0.485 \\
\hline
\end{tabular}


FEA software. The modeling of retreatment files was done according to previous studies. ${ }^{7}$

The behavior of the retreatment files was analyzed numerically in the FEA package (ANSYS). The stress distribution on the surface and within the instrument was evaluated. The screw-in tendency, measured as the force acting on the file in an apical direction, was recorded. Each retreatment file was used in sequence according to the manufacturer's instruction.

\section{RESULTS}

Figure 1 shows the maximum stress values of ProTaper Universal retreatment system. The D1 file received the maximum stress value in the cervical third, and the D2 file received the least stress value in the middle third.

Figure 2 shows the maximum stress values of Mtwo retreatment system. The $\mathrm{R} 2$ file received the maximum stress value in the cervical third and the least stress value in the middle third.

Table 2 shows comparative maximum stress values of the retreatment files in the cervical, middle, and in the apical third. In the cervical third, the Mtwo retreatment system received the maximum stress and the ProTaper retreatment system received the least stress. In the middle third, the Mtwo retreatment system file received the maximum stress and the ProTaper retreatment system received the least stress. In the apical third, the ProTaper retreatment system received the maximum stress and the Mtwo retreatment system received the least stress.

\section{DISCUSSION}

There has been an increasing use of rotary retreatment file systems owing to their efficiency and speed in the retrieval of gutta-percha, but it is important to understand the magnitude of stresses on the instrument to prevent its fracture in clinical use. The determination of stress generated along the instrument or any residual stresses contributing to instrument fracture cannot be determined during actual clinical use. Hence, a mathematical simulation was used to estimate the stress distribution on the instrument. ${ }^{9}$

Several methods have been used to study the stress distribution of structural objects with complex morphology:
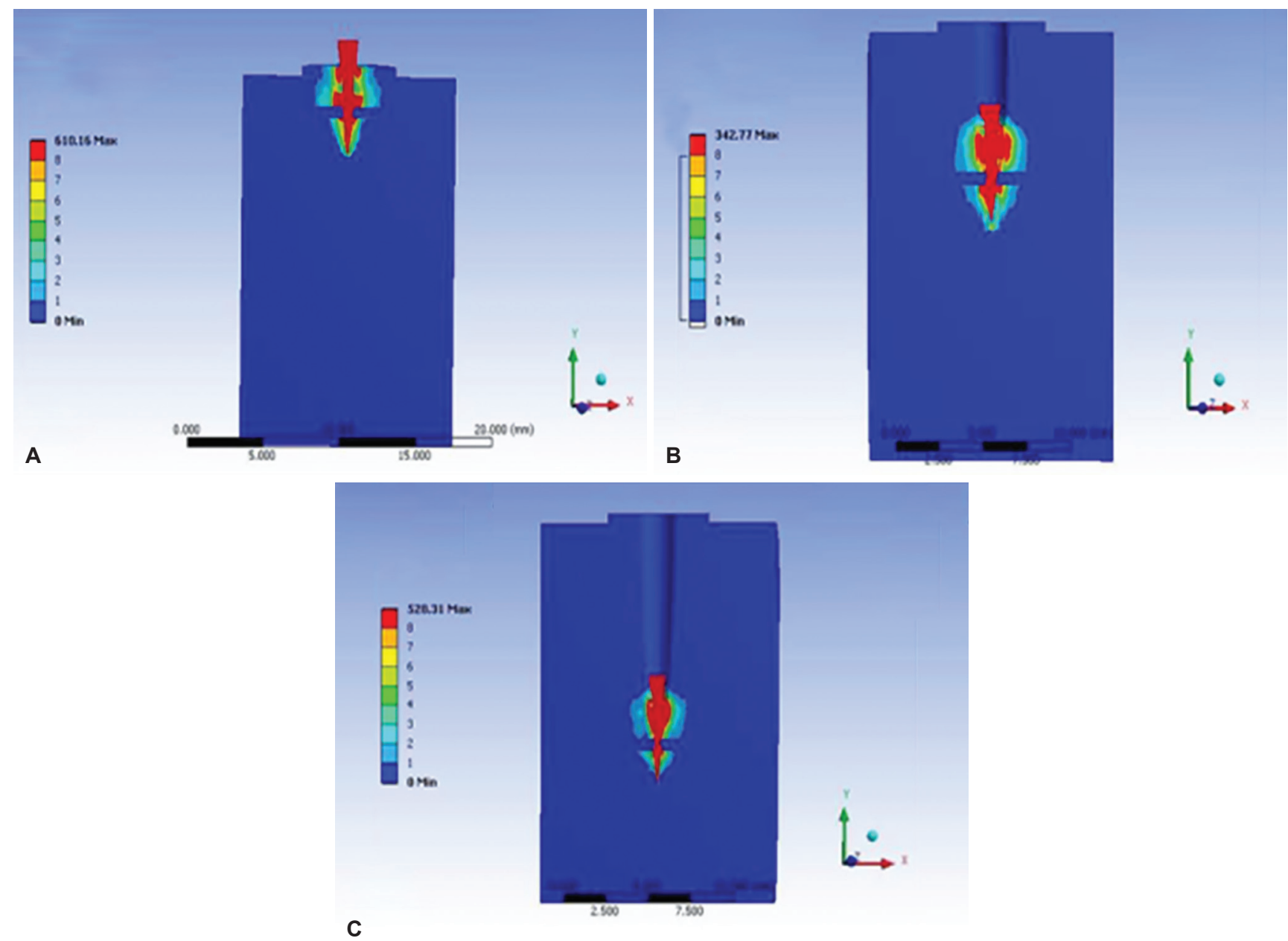

Figs 1A to C: Maximum stress on ProTaper retreatment file (A) Instrument receiving maximum stress before fracture in cervical third; $(B)$ instrument receiving maximum stress before fracture in middle third; and $(C)$ instrument receiving maximum stress before fracture in apical third 


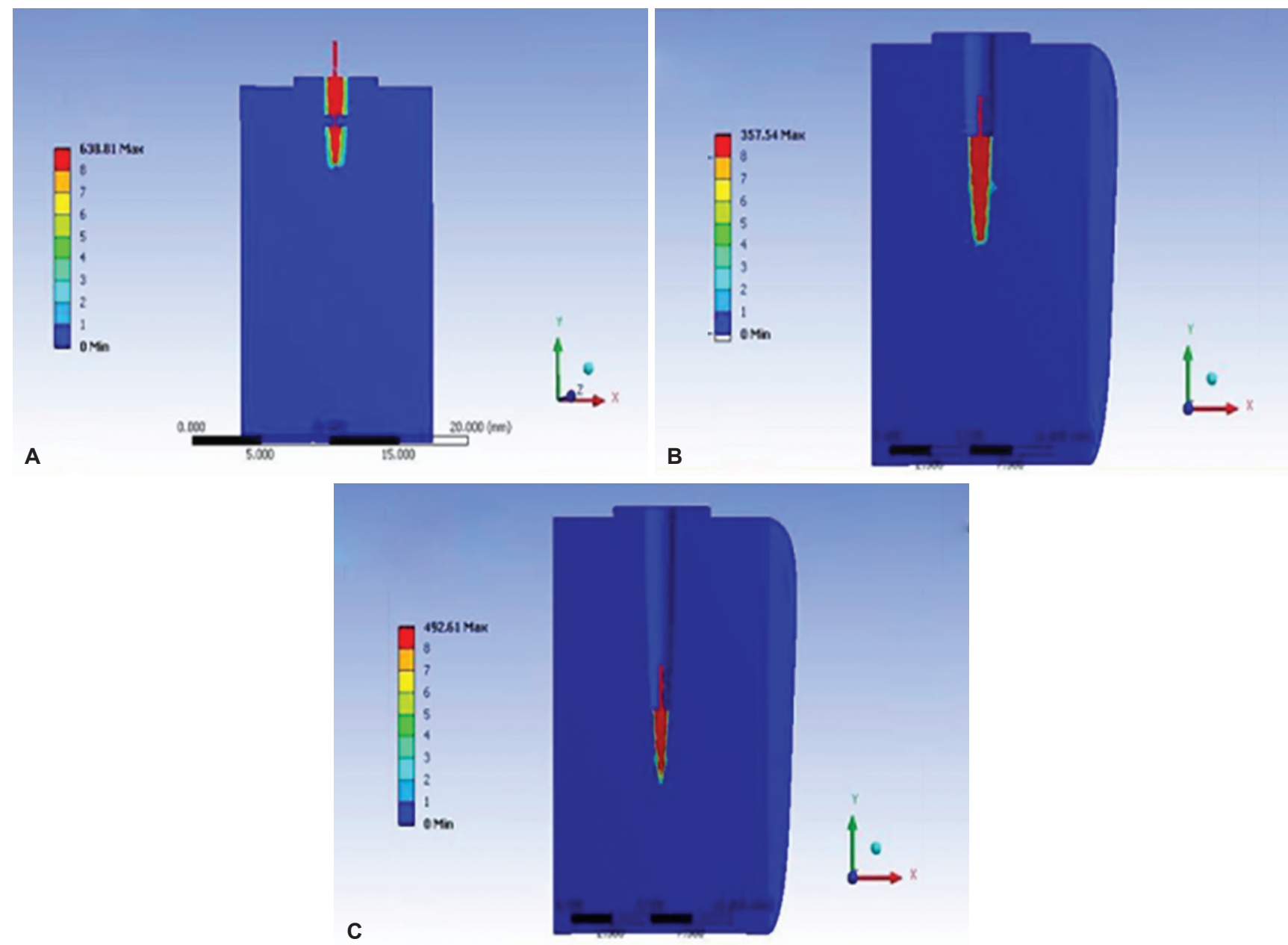

Figs 2A to C: Maximum stress on Mtwo retreatment file (A) Instrument receiving maximum stress before fracture in cervical third; (B) instrument receiving maximum stress before fracture in middle third; and $(C)$ instrument receiving maximum stress before fracture in apical third

Table 2: Comparison of stress distribution on the retreatment files

\begin{tabular}{lll}
\hline & $\begin{array}{l}\text { Retreatment } \\
\text { instrument }\end{array}$ & $\begin{array}{l}\text { Maximum stress } \\
\text { developed (MPa) }\end{array}$ \\
\hline Cervical third & ProTaper & 610 \\
& Mtwo & 638 \\
Middle third & ProTaper & 342 \\
& Mtwo & 357 \\
Apical third & ProTaper & 528 \\
& Mtwo & 492 \\
\hline
\end{tabular}

The strain gauge technique, photoelastic test, and the finite element method. Finite element analysis has been widely used in the field of structural-mechanical analysis. In FEA, a large structure is divided into small units, for which individual deformation (strain and stress) can be easily calculated. By solving the deformation of all the small units simultaneously, the deformation of the whole structure can be assessed. ${ }^{12}$ Hence, FEA was used in this study.

The retreatment file systems, ProTaper and Mtwo, were compared and the stress distribution was analyzed by FEA.
The ProTaper retreatment files (D1, D2, and D3) are designed for removing filling materials from the root canals. They have a convex cross section but D1 has a working tip that facilitates its penetration into filling materials. ${ }^{6}$

In the Mtwo file system, the pitch of the instrument is increased from the tip to the handle, and the depth of the space designed for dentin removal is increased behind the blades, which provides the largest space for dentin removal and more efficient gutta-percha and the sealer removal. It works in an $\mathrm{H}$ file-like motion (up and down) and has a positive rake angle similar to the $\mathrm{H}$-file, making dentin removal efficient. The system comprises two \#25 files with 0.05 taper in the coronal and a \#15 file with 0.05 taper in the middle and apical sections. The active cutting tip of the instrument and the thin cross-sectional diameter act as stress raisers over the cutting blade of the instrument. ${ }^{8}$

In the cervical third, an increase in density and well adaptation of the gutta-percha to the canal walls created a maximum stress value of $610 \mathrm{MPa}$ on the ProTaper D1 instrument during retreatment. The Mtwo retreatment files received a maximum stress value of $638 \mathrm{MPa}$. 
The stress developed on the instrument in the middle third is half the stress developed on the retreatment instrument in the cervical third. Due to the frictional heat produced during retreatment of gutta-percha from the cervical third, gutta-percha is within the elastic limit in the middle third; hence, the torque developed by the guttapercha on the retreatment instrument is half of that in the cervical third. D2 received stress value of $342 \mathrm{MPa}$ during treatment and Mtwo R2 showed a value of $357 \mathrm{MPa}$.

The noncutting tip D3 is used to remove the guttapercha from the apical third. The instrument used till the apical third of the root canal experienced torque over the entire cutting edge of the instrument; hence, the stress developed over the instrument during retreatment of gutta-percha in the apical third is higher than the middle third. The torque developed over the instrument is mainly due to the dentinal wall rather than by the gutta-percha. Hence, the stress value is $528 \mathrm{MPa}$. The Mtwo retreatment instrument received a greater torque over the entire length of the blade; hence, the stress values are higher during retreatment in the apical third than in the middle third. A maximum stress of $492 \mathrm{MPa}$ was recorded.

According to previous studies, the maximum stress value in the files decreases with increasing torsional inertia of the cross section, and the stress distribution is strongly related to the width of the radial land and the peripheral surface ground. The peripheral strength of the model is increased with a wider radial land, leading to greater friction when cutting dentin clinically, indicating that by increasing the inner core of the cross section, the torque resistance of an endodontic file can be enhanced..$^{13}$ This could be the reason why the ProTaper retreatment system generated less stress compared with the Mtwo system.

The results of FEA potentially contribute to innovative designs in endodontic instruments and also help in estimating the maximum stress developed during retreatment. Despite being a useful technique, the FEA possesses certain limitations. In actual clinical use, the solvent is used to soften the gutta-percha, which may produce less resistance to removal by the retreatment system. Using FEA, the gutta-percha solvent cannot be modeled, hence, the stresses generated on the retreatment instrument may differ in actual clinical use of the retreatment system.

Another drawback of the FEA technique is that it is based on several assumptions. Dentin is a complex biomaterial created and changed over time with varied properties in different areas. Some of the parameters used in FEA calculation like Poisson's ratio, Young's modulus, hardness, compressive and shear strength of dentin vary in different areas depending on mineral content. The FEA assumes that dentin is a uniform, isotropic material: Its properties do not differ when tested in different areas or directions. ${ }^{14-16}$
Although FEA is associated with various limitations and assumptions, earlier studies have shown that FEA is reasonably reliable in prediction of fracture patterns ${ }^{17,18}$ and also individual variables and combinations of variables can be systematically analyzed in ways not possible experimentally. ${ }^{19}$

\section{CONCLUSION}

Within the limitations of the study, it can be concluded as follows:

- Retreatment instruments received the greatest stress in the cervical third, followed by the apical third and the middle third.

- The ProTaper Universal retreatment system generated least stress during retreatment compared with Mtwo retreatment system.

There is no instrument system, i.e., suitable for all clinical situations, and it is important to understand how the structural characteristics could influence the magnitude of stresses on the instrument to prevent its fracture in use. Further in vivo and in vitro studies are necessary to evaluate the relationship between instrument designs, stress distribution, residual stresses after use, and the torsional fracture of the retreatment instrument.

\section{REFERENCES}

1. Wong R. Conventional endodontic failure and retreatment. Dent Clin North Am 2004 Jan;48(1):265-289.

2. Saad AY, Al-Hadlaq SM, Al-Katheeri NH. Efficacy of two rotary NiTi instruments in the removal of gutta-percha during root canal retreatment. J Endod 2007 Jan;33(1):38-41.

3. Giuliani V, Cocchetti R, Pagavino G. Efficacy of ProTaper universal retreatment files in removing filling materials during root canal retreatment. J Endod 2008 Nov;34(11):1381-1384.

4. Schirrmeister JF, Wrbas KT, Meyer KM, Altenburger MJ, Hellwig E. Efficacy of different rotary instruments for guttapercha removal in root canal retreatment. J Endod 2006 May;32(5):469-472.

5. Só MV, Saran C, Magro ML, Vier-Pelisser FV, Munhoz M. Efficacy of ProTaper retreatment system in root canals filled with gutta-percha and two endodontic sealers. J Endod 2008 Oct;34(10):1223-1225.

6. Gu LS, Ling JQ, Wei X, Huang XY. Efficacy of ProTaper universal rotary retreatment system for gutta-percha removal from root canals. Int Endod J 2008 Apr;41(4):288-295.

7. Kim TO, Cheung GS, Lee JM, Kim BM, Hur B, Kim HC. Stress distribution of three NiTi rotary files under bending and torsional conditions using a mathematic analysis. Int Endod J 2009 Jan;42(1):14-21.

8. Iriboz E, Sazak Öveçoğlu H. Comparison of ProTaper and Mtwo retreatment systems in the removal of resin-based root canal obturation materials during retreatment. Aust Endod J 2014 Apr;40(1):6-11.

9. Kim HC, Cheung GS, Lee CJ, Kim BM, Park JK, Kang SI. Comparison of forces generated during root canal shaping and residual stresses of three nickel-titanium rotary files by using a three-dimensional finite-element analysis. J Endod 2008 Jun;34(6):743-747. 
10. Cheng R, Zhou XD, Liu Z, Yang H, Gao QH, Hu T. Finite element analysis of the effects of three preparation techniques on stresses within roots having curved canals. Int Endod J 2009 Mar;42(3):220-226.

11. Telli C, Gülkan P, Raab W. Additional studies on the distribution of stresses during vertical compaction of gutta-percha in the root canal. Br Dent J 1999 Jul;187(1):32-37.

12. Srirekha A, Bashetty K. Infinite to finite: an overview of finite element analysis. Indian J Dent Res 2010 Jul-Sep;21(3):425-432.

13. Turpin $Y L$, Chagneau F, Vulcain JM. Impact of two theoretical cross-sections on torsional and bending stresses of nickel-titanium root canal instrument models. J Endod 2000 Jul;26(7):414-417.

14. Kinney JH, Balooch M, Marshall SJ, Marshall GW Jr, Weihs TP. Hardness and Young's modulus of human peritubular and intertubular dentin. Arch Oral Biol 1996 Jan;41(1):9-13.
15. Smith DC, Cooper WE. The determination of shear strength. A method using a micro-punch apparatus. Br Dent J 1971 Apr;130(8):333-337.

16. Konishi N, Watanabe LG, Hilton JF, Marshall GW, Marshall SJ, Staninec M. Dentin shear strength: effect of distance from the pulp. Dent Mater 2002 Nov;18(7):516-520.

17. Lertchirakarn V, Palamara JE, Messer HH. Patterns of vertical root fracture: factors affecting stress distribution in the root canal. J Endod 2003 Aug;29(8):523-528.

18. Sathorn C, Palamara JE, Messer HH. A comparison of the effects of two canal preparation techniques on root fracture susceptibility and fracture pattern. J Endod 2005 Apr;31(4): 283-287.

19. Lertchirakarn V, Palamara JE, Messer HH. Load and strain during lateral condensation and vertical root fracture. J Endod 1999 Feb;25(2):99-104. 